Article

\title{
Impact of Environmental Regulations on Environmental Quality and Public Health in China: Empirical Analysis with Panel Data Approach
}

\author{
Liwei Tang ${ }^{1,2,3}$, Ke Li ${ }^{1,2,3}$ and Pinrong Jia ${ }^{4, *}$ \\ 1 Key Laboratory of Computing and Stochastic Mathematics (Ministry of Education), Hunan Normal \\ University, Changsha 410081, China \\ 2 Key Laboratory of Applied Statistics and Data Science, Hunan Normal University, Changsha 410081, China \\ 3 School of Mathematics and Statistics, Hunan Normal University, Changsha 410081, China; \\ liweitang@hunnu.edu.cn (L.T.); likekent1208@163.com (K.L.) \\ 4 Beijing Research Center for Science of Science, Beijing 100054, China \\ * Correspondence: jiapinrong@163.com; Tel.: +86-138-013-08610
}

Received: 21 October 2019; Accepted: 11 January 2020; Published: 15 January 2020

check for updates

\begin{abstract}
Achieving high-quality environmental development through environmental regulations and thus enhancing public health is a goal of the Chinese government. Based on the panel data of 30 Chinese provinces from 1998 to 2017, this study demonstrates the co-benefits of environmental regulations on air quality, water, and public health through a panel Granger causality model and mediation effect model. The findings indicate that environmental regulations have a Granger causal effect on public health costs and air and water pollution. Furthermore, the results from the mediation effect model suggest that waste gas treatment could improve air quality, thus reducing public health costs; wastewater treatments could not only reduce public health costs through improvement of the water environment but also increase social welfare. Additionally, air pollution exhibits a greater negative externality impact on health than water pollution. Thus, environmental regulation policies should pay more attention to air pollution control. The findings of this study indicate that environmental regulations have a significant co-benefit on high-quality environmental development and public health.
\end{abstract}

Keywords: environmental high-quality development; health co-benefits; environmental regulations; mediation effect

\section{Introduction}

In recent years, health losses due to environmental pollution have received much attention in public and academic circles. Relevant studies have shown that environmental pollution significantly increases the cost of health care and the number of deaths, and reduces life expectancy [1-3]. According to the World Health Report 2013, approximately 25\% of the global burden of disease can be attributed to environmental risks, such as indoor and outdoor air pollution. Furthermore, the latest Global Burden of Disease study revealed that approximately 2.9 million people worldwide died prematurely due to fine particulate matter $\left(\mathrm{PM}_{2.5}\right)$ pollution in 2013 [2,4] and the number of premature deaths worldwide reached 4.2 million in 2015 [5,6]. The above facts indicate that improving environmental quality can significantly reduce health risks and increase social welfare.

According to the latest data from the global urban pollution database of the World Health Organization, in 2014, 10 of the 20 most polluted cities were in China. Another result, after the 2016 air quality monitoring conducted by the Ministry of Environmental Protection of China, indicated that only 84 of the 338 prefecture-level cities have better ambient air quality than the national secondary standard 
(the Ambient air quality standards (GB 3095-2012) explained the details of the standard, including $\mathrm{SO}_{2}$, $\mathrm{NO}_{2}, \mathrm{CO}, \mathrm{O}_{3}, \mathrm{PM}_{2.5}$, and so on, such as the need to maintain $\mathrm{PM}_{2.5}$ below $75 \mu \mathrm{g} / \mathrm{m}^{3}$ to reach the national secondary standard). In addition, related studies have found that the number of premature deaths caused by air pollution in China may reach 1.65 million per year [7]. Due to the negative externalities of environmental pollution, environmental regulation is considered an important policy tool for effectively improving environmental quality and reducing health risks [8-10]. While the positive environmental consequences of environmental regulation policies are widely acknowledged, little is known about the effects of these policies on public health. What are the effects of environmental regulations on social welfare? To answer this question, this study investigates environmental regulations' impact on environmental quality and their co-benefits on health through decreasing environmental pollution. Furthermore, the social risks associated with environmental degradation have far-reaching impacts on developing countries, and many of these are serious or irreversible. Therefore, when one is analyzing the co-benefits of environmental regulations on environmental quality and health, China, the largest developing country in the world, can undoubtedly serve as an important reference for how to improve social welfare and how to promote the sustainable development of developing countries.

The contributions of this study are the combing of environmental regulations with public health through the intermediary role of environmental pollution, and the quantitative evaluation of the three-dimensional relationship between environmental regulations, environmental quality, and public health. In particular, (1) with respect to research content, most studies have explored the impact of environmental pollution on health and that of environmental regulations on pollutant emissions reduction; few have looked at the impact of environmental regulations on public health. Therefore, in this study, environmental quality is taken as a "bridge" to assess the co-benefits of environmental regulations on public health through the improvement in environmental quality. (2) In terms of research methods, a heterogeneity panel data Granger causality model and a mediation effect model are adopted to test the mechanism "environmental regulations $\rightarrow$ environmental quality $\rightarrow$ health level", that environmental regulations can create health co-benefits through improvement in environmental quality. Furthermore, this study can provide important policy reference for China as well as for developing countries, to formulate and optimize their environmental regulation policies.

The remainder of this paper is structured as follows: Section 2 is the literature review, Section 3 presents the design of the empirical model and data description, Section 4 is the analysis of the empirical results, and Section 5 is the conclusion and policy applications.

\section{Literature Review}

\subsection{Impact of Environmental Pollution on Health}

The relationship between environmental pollution and health has been widely discussed. Generally, mortality, life expectancy or health expenditure are adopted to measure health. Beatty and Shimshack [11] found that an increase in carbon monoxide and ground-level ozone was associated with a significant increase in children's contemporaneous respiratory treatments. Arceo, et al. [1] used data from a Mexican sample to show that air pollution can significantly increase infant mortality. Similar findings were revealed by Chen, et al. [12] and Kim, et al. [13]. Studies using life expectancy as a proxy for health by Chen, et al. [3] and Ebenstein, et al. [14] can also be found. They used the Huai river heating boundary formed by China's heating policy, as a cut-off point and found that air pollution leads to reduction in life expectancy. Ebenstein, et al. [15] also found that $\mathrm{PM}_{10}$ has a negative impact on life expectancy. Moreover, Yang and Zhang [2] used the China Urban Household Survey (UHS) Database and estimated the effects of air pollution exposure on household healthcare expenditure- this is the latest study using health expenditure as a proxy for health. 


\subsection{Impact of Environmental Regulations on Environmental Pollution}

Whether environmental regulations can reduce environmental pollution is a popular issue in recent environmental economics research. A large number of studies have shown that environmental regulations can improve environmental quality [10,16-19]; however, some studies have shown that there is no effect. Greenstone [20] studied the effect of the Clean Air Act, issued by the United States in 1970, on $\mathrm{SO}_{2}$ emissions. The findings suggested that the environmental regulations policy did not significantly reduce $\mathrm{SO}_{2}$ emissions, and a series of robust analyses supported the conclusions. The author believed that a county's nonattainment designation and whether its ambient $\mathrm{SO}_{2}$ concentration exceeds the federal standards might be the reasons behind it. Wang, et al. [21] found that the environmental regulations for water pollution control in the "three rivers and three lake basins" in China did not reduce the chemical oxygen demand emissions of the surviving companies.

\subsection{Impact of Environmental Regulations on Health}

Few studies have investigated the impact of environmental regulations on health. Greenstone and Hanna [17] showed that environmental regulations did not significantly reduce infant mortality. On the other hand, using data from India, Do, et al. [9] found that environmental policies significantly reduced infant and child mortality. Jones [8] studied the positive externalities generated by the 2009 Los Angeles LED Street Light Efficiency Program. Cesur, et al. [22] suggested that the substitution of natural gas for coal in Turkey significantly decreased both adult and elderly mortality rates. Another study by Cesur, et al. [23] also obtained similar findings. Tanaka [24] found that the environmental regulations had decreased infant mortality rate significantly in the treatment group cities by using China's data.

Based on the above review, it can be seen that most studies covered bilateral relations within environmental regulations, environmental quality, and health; however, a few quantitatively examined the relationship between these three factors, i.e., the mechanism "environmental regulations $\rightarrow$ environmental quality $\rightarrow$ health level". Therefore, this study takes China as a case study and attempts to create a detailed quantitative test for the above mechanism; the results shed new light on the emission reduction effects of environmental regulations and these regulations' positive externalities, especially for developing countries.

\section{Empirical Model and Data}

This study uses the sampled data of 30 Chinese provinces from 1998 to 2017 for empirical analysis. To test the mechanism "environmental regulations $\rightarrow$ environmental quality $\rightarrow$ health level", waste gas treatment investment, wastewater treatment investment, and total environmental treatment investment are taken as environmental regulations. Furthermore, this study uses $\mathrm{PM}_{2.5}$ and wastewater as proxies for environmental quality or environmental pollution and public health costs as a proxy for health. The processing and source of specific indicators are explained in detail below.

\subsection{Mediation Effect Model}

Most of the literature and epidemiological theory suggest that environmental pollution has a negative effect on health. In other words, the better the environmental quality, the better the heath. Therefore, if environmental regulations play a role in promoting environmental quality improvement, then the resulting environmental quality can further produce positive health effects. To reveal the mechanism "environmental regulations $\rightarrow$ environmental quality $\rightarrow$ health level", this study adopted a mediation effect model, which is the stepwise test proposed by Baron and Kenny [25]. It tests the influence of the independent variable $X$ on the dependent variable $Y$. If $X$ affects $Y$ via the variable $Z$, then $Z$ is called the intermediate variable. Specifically, this mechanism can be represented as follows:

$$
\begin{aligned}
& Y=c X+\varepsilon_{1} \\
& Z=a X+\varepsilon_{2}
\end{aligned}
$$




$$
Y=c^{\prime} X+b Z+\varepsilon_{3}
$$

According to Shao, et al. [26], Wen and Ye [27] and Fritz, et al. [28], the mediation effect test can be described as follows. First, the coefficient $c$ in Equation (1) is tested; whether or not it is significant, the next test is conducted, where $c$ represents the total effect of the independent variable $X$ on $Y$. Second, the coefficients $a$ and $b$ in Equations (2) and (3) are tested, where $a$ represents the effect of the independent variable $X$ on the intermediate variable $Z$, and $b$ is the effect of the intermediate variable $Z$ on the dependent variable $Y$ after controlling for the independent variable $X$. If both are significant, a mediation effect exists. Finally, the coefficient $c^{\prime}$ in Equation (3) is tested. If $c^{\prime}$ is significant, this implies a significant direct effect, also known as a partial mediation effect. If $c^{\prime}$ is not significant, this indicates that only a mediation effect exists.

Following Yang et al. [29] and Yang and Zhang [2], this study uses public health costs (health) as the explanatory variable $Y$, i.e., as a proxy index of the health level. Environmental pollution (env) is taken as the intermediate variable $Z$ and environmental regulations (regulation) as the explanatory variable $X$. Therefore, the mediation effect model can be set as follows:

$$
\begin{gathered}
\text { health }_{i t}=\mu_{i}+\text { dregulation }_{i t}+\varepsilon_{1 t} \\
\text { env }_{i t}=\tau_{i}+\text { rregulation }_{i t}+\varepsilon_{2 t} \\
\text { health }_{i t}=\eta_{i}+\delta^{\prime} \text { regulation }_{i t}+\theta e n v_{i t}+\varepsilon_{3 t}
\end{gathered}
$$

Equations (4) through (6) correspond to Equations (1) through (3), where $i$ denotes the province and $t$ denotes the year. The focus of this study is the public health costs due to environmental pollution; therefore, the public health level measured in this study only considers the diseases that residents seek treatment for. It is measured by medical expenditure and does not take into account the increased in cure rate and longevity due to advanced technology and increased medical resources [29]. Specifically, this study used the healthcare expenditure of urban residents to measure the public health costs and adjusts it to a 2000-based price by using the Consumer Price Index (CPI).

For environmental pollution (env), it is widely believed that, among all the types, air pollution is most likely to cause pathogenicity. Also, $\mathrm{PM}_{2.5}$ has become one of the most important factors influencing global death risk factors [6]. Water is the source of life, and people need a certain amount of it daily to maintain a balance in body functions. Therefore, water pollution also has a negative impact on health. Thus, this study uses $\mathrm{PM}_{2.5}$ and per capita wastewater discharge to measure environmental pollution, and they are indicated as pm 25 and pwater, respectively.

With respect to the availability of data, to measure environmental regulations, most of the literature mainly uses the number of environmental laws, pollution control investment as a proportion of enterprise costs or output value, pollution control costs, and the number of regulatory agencies or inspections [30-36]. It is not reasonable to adopt the absolute quantity indicator to measure environmental regulations due to the heterogeneity of Chinese provinces. Therefore, to measure environmental regulations, this study used the relative quantity indicator-the proportion of waste gas, wastewater, and industrial pollution control costs in industrial enterprises' main business costs and main business income. The corresponding variables are sogovcost, sogovinc, watergovcost, watergovinc, pollgovcost and pollgovinc, respectively. $\mu_{i}, \tau_{i}$, and $\eta_{i}$ are the individual fixed effects, respectively; $\delta, \beta_{i}, \gamma, \delta^{\prime}, \theta$, and $\phi_{i}$ are the parameters that were estimated in the model and $\varepsilon_{1 t}, \varepsilon_{2 t}$, and $\varepsilon_{3 t}$ are the random disturbances.

\subsection{Unit Root Tests and Granger Causality Test}

To avoid the pseudo-regression that would lead to erroneous research conclusions, this study first tested the unit root of all the variables that is used before estimating Equation (4) through $(6)[37,38]$. If no unit roots existed, the Granger causality test was performed. If a unit root existed, it was necessary to further check whether there was a cointegration relationship before the Granger causality test. 
When the Granger causality test indicated a Granger causality among the variables in Equation (4) through (6), then these equations were estimated and assessed for the existence of a mediating effect. It should be noted that the Granger causality test does not indicate true causal relationships; it describes the dynamic correlation among economic variables (it is a statistical hypothesis for determining whether one time series or panel data is useful for forecasting another). In other words, if the relationships described in Equation (4) through (6) are established, significant Granger causality exists among them.

Since the sampled period in this study was short, it used the unit root test proposed by Harris and Tzavalis [39] (HT), which is suitable when $T$ is fixed and $N$ is larger than $T$. The HT test is based on the OLS estimator, $\rho$, in the regression model:

$$
y_{i t}=\rho y_{i t-1}+\mathbf{z}_{i t}^{\prime} \gamma_{i}+\varepsilon_{i t}
$$

where the term $\mathbf{z}_{i t}^{\prime} \gamma_{i}$ allows for panel-specific means and trends [40], $i=1, \ldots, N, t=1, \ldots, T, \varepsilon_{i t}$ are the random disturbances. The HT test that $\sqrt{N}(\hat{\rho}-\mu) \stackrel{D}{\rightarrow} N\left(0, \sigma^{2}\right)$ as $N \rightarrow \infty$ with $T$ fixed, where $\mu$ and $\sigma^{2}$ depend on the specification of the deterministic component [40]. The details can be found in $[39,40]$. In addition, to ensure the robustness of the results, this study also used the unit root test proposed by Im, et al. [41] (IPS) to test the stationarity of the variables. The final statistics of the IPS test are like of a $t$ test. It is more complicated to introduce the IPS test, details of which can be found in $[40,41]$. For the Granger causality test, this study referred to Dumitrescu and Hurlin [42]. The model was as follows:

$$
y_{i t}=\mu_{i}+\sum_{k=1}^{K} \beta_{i k} y_{i, t-k}+\sum_{k=1}^{K} \gamma_{i k} x_{i, t-k}+\varepsilon_{i t}
$$

where $K$ is the lag order and the panel must be balanced, $\mu_{i}$ is the fixed effect, $\varepsilon_{i t}$ is the random disturbances, $i=1, \ldots, N, t=1, \ldots, \mathrm{T}$.

Thus, whether $x$ had a Granger causal effect on $y$ could be tested through the following null hypothesis:

$$
H_{0}: \gamma_{i 1}=\gamma_{i 2}=\ldots=\gamma_{i K}=0, \quad \forall i=1, \ldots, N
$$

If the above null hypothesis could not be rejected, then there was no Granger causal effect of $x$ on $y$. Otherwise, it may exist for some individuals. Dumitrescu and Hurlin [42] constructed a $\bar{W}$ statistic when examining Equation (8), which is the average of the $N$ sections' individual Wald statistics. The $\bar{W}$ statistic is defined as follows:

$$
\bar{W}=\frac{1}{N} \sum W_{i}
$$

Using Monte Carlo simulations, Dumitrescu and Hurlin [42] showed that $\bar{W}$ can be used as the test statistic to test the Granger causal effect. In addition, $\bar{W}$ can be transformed to a standardized statistic $\bar{Z}$ when $T \rightarrow \infty$ first, followed by $N \rightarrow \infty . \bar{Z}$ follows a standard normal distribution:

$$
\bar{Z}=\sqrt{\frac{N}{2 K}} \cdot(\bar{W}-K) \underset{T, N \rightarrow \infty}{\stackrel{d}{\longrightarrow}} \mathrm{N}(0,1)
$$

For a fixed $T$ with $T>5+3 K$, the statistic $\widetilde{Z}$ also follows a standard normal distribution:

$$
\widetilde{Z}=\sqrt{\frac{N}{2 K} \cdot \frac{T-3 K-5}{T-2 K-3}}\left[\frac{T-3 K-3}{T-3 K-1} \cdot \bar{W}-K\right] \underset{N \rightarrow \infty}{\stackrel{d}{\longrightarrow}} \mathrm{N}(0,1)
$$

If $\bar{Z}$ and $\widetilde{Z}$ are larger than the corresponding normal critical values, then the $\mathrm{H}_{0}$ in Equation (8) should be rejected, which means there is Granger causality.

Following the model of Dumitrescu and Hurlin [42], the test models for the Granger causal effect in this study were as follows. 


$$
\begin{gathered}
\text { health }_{i t}=\mu_{i}+\sum_{k=1}^{K} \beta_{i k} \text { health }_{i, t-k}+\sum_{k=1}^{K} \gamma_{i k} \text { regulation }_{i, t-k}+\varepsilon_{i t} \\
\text { env }_{i t}=\mu_{i}^{\prime}+\sum_{k=1}^{K^{\prime}} \beta_{i k}^{\prime} e^{\prime} v_{i, t-k}+\sum_{k=1}^{K^{\prime}} \gamma_{i k}^{\prime} \text { regulation }_{i, t-k}+\varepsilon_{i t}^{\prime} \\
\text { health }_{i t}=\mu_{i}^{\prime \prime}+\sum_{k=1}^{K^{\prime \prime}} \beta_{i k}^{\prime \prime} \text { health }_{i, t-k}+\sum_{k=1}^{K^{\prime \prime}} \gamma_{i k}^{\prime \prime} \text { env }_{i, t-k}+\varepsilon_{i t}^{\prime \prime} \\
\text { health }_{i t}=\mu_{i}^{\prime \prime \prime}+\sum_{k=1}^{K^{\prime \prime \prime}} \beta_{i k}^{\prime \prime \prime} \text { health }_{i, t-k}+\sum_{k=1}^{K^{\prime \prime \prime}} \gamma_{i k}^{\prime \prime \prime} \text { regulation }_{i, t-k}+\sum_{k=1}^{K^{\prime \prime \prime}} \gamma_{i k}^{\prime \prime \prime} \text { env }_{i, t-k}+\varepsilon_{i t}^{\prime \prime \prime}
\end{gathered}
$$

\subsection{Data}

With respect to availability of data, the sample data used in this study were panel data of 30 Chinese provinces from 1998 to 2017. These did not include Hong Kong, Macao, Taiwan, and Tibet. All data were from the China Statistical Yearbook and China Statistical Yearbook on Environment. Variables that needed a price adjustment were based on the 2000 price. In the empirical analysis, this study used the logarithm transformation on absolute quantity variables to reduce the dispersion of the sample and the possibility of heteroscedasticity. In addition, one of the environmental pollution indicators used in this study was the $\mathrm{PM}_{2.5}$ concentration values. As the Chinese $\mathrm{PM}_{2.5}$ concentration data did not include monitoring data until after 2013, this study used satellite monitoring data for cities, estimated by the Batt Institute and International Earth Science Information Network Center of Columbia University from 1998 to 2016 [43]. Additionally, the $\mathrm{PM}_{2.5}$ concentration data of 2017 were averaged at the provincial level by using the prefecture-level data, which were from the Ministry of Ecology and Environment of the People's Republic of China Database. Furthermore, in the empirical analysis, social health cost, $\mathrm{PM}_{2.5}$, and per capita wastewater emissions were used logarithmically. Descriptive statistics for each variable are shown in Table 1.

Table 1. Descriptive statistics of variables.

\begin{tabular}{ccccccc}
\hline Variable & Name & Unit & Mean & Sd & Min & Max \\
\hline health & Social health cost & Yuan & 652.04 & 343.21 & 108.22 & 2253.14 \\
pm25 & Particulate matter $\left(\mathrm{PM}_{2.5}\right)$ & $\mu \mathrm{g} / \mathrm{m}^{3}$ & 31.89 & 15.89 & 5.32 & 81.93 \\
pwater & Per capital wastewater emissions & ton & 46.827 & 39.820 & 0.723 & 567.228 \\
pollgovcost & Pollutants/main business costs & $\%$ & 0.225 & 0.194 & 0.008 & 1.280 \\
watergovcost & Wastewater treatment/main business costs & $\%$ & 0.075 & 0.090 & 0.000 & 0.810 \\
sogovcost & Waste gas treatment/main business costs & $\%$ & 0.112 & 0.109 & 0.001 & 0.739 \\
pollgovinc & Pollutants treatment/main business incomes & $\%$ & 0.180 & 0.154 & 0.007 & 1.080 \\
watergovinc & Wastewater treatment/main business incomes & $\%$ & 0.060 & 0.072 & 0.000 & 0.683 \\
sogovinc & Waste gas treatment/main business income & $\%$ & 0.090 & 0.088 & 0.001 & 0.626 \\
\hline
\end{tabular}

Notes: The sample covers 30 Chinese provinces from 1998 to 2017.

\section{Results}

\subsection{Results of Unit Root Test and Granger Causality Test}

The unit root tests are shown in Table 2, which shows that all variables are stationary sequences, so the combination of arbitrary variables for the Granger causality test satisfies the precondition. Table 3 presents the results of the Granger causality test of two of the variables by using the full data. When using $\mathrm{PM}_{2.5}$ to measure environmental pollution, the upper part of Table 3 shows that there are Granger causal effects of environmental regulations on public health costs and environmental pollution, and the former effect is significant. When per capita wastewater discharge is adopted to 
measure environmental pollution, the lower part of Table 3 show that environmental regulations have a moderate Granger causal effect on public health costs (the corresponding $p$ value of the $\bar{Z}$ statistic is small, and the probability of the Granger causal effect is 1-p), and there is a Granger causal effect by environmental regulations on environmental pollution. Also, environmental pollution has a Granger causal effect on public health costs.

Table 2. The outcome of unit root test (1998-2017).

\begin{tabular}{ccccc}
\hline \multirow{2}{*}{ Variables } & \multicolumn{2}{c}{ HT Test } & \multicolumn{2}{c}{ IPS Test } \\
\cline { 2 - 5 } & No Trend & Trend & No Trend & Trend \\
\hline lhealth & $2.832^{* * *}$ & $-3.400^{* * *}$ & $-7.369^{* * *}$ & $-10.863^{* * *}$ \\
sogovcost & $-20.554^{* * * *}$ & $-13.368^{* * *}$ & $-8.382^{* * *}$ & $-8.044^{* * *}$ \\
watergovcost & $-11.041^{* * *}$ & $-13.193^{* * *}$ & $-7.775^{* * *}$ & $-10.659^{* * *}$ \\
pollgovcost & $-13.851^{* * *}$ & $-13.824^{* * *}$ & $-8.480^{* * *}$ & $-9.688^{* * *}$ \\
watergovinc & $-10.966^{* * *}$ & $-13.077^{* * *}$ & $-9.005^{* * *}$ & $-9.506^{* * *}$ \\
sogovinc & $-21.045^{* * *}$ & $-13.416^{* * *}$ & $-8.953^{* * *}$ & $-8.554^{* * *}$ \\
pollgovinc & $-14.410^{* * *}$ & $-13.824^{* * *}$ & $-8.277^{* * *}$ & $-8.113^{* * *}$ \\
lpm25 & $-8.031^{* * *}$ & $-6.500^{* * *}$ & $-7.235^{* * *}$ & $-6.627^{* * *}$ \\
lpwater & $-19.221^{* * *}$ & $-14.698^{* * *}$ & $-12.349^{* * *}$ & $-21.461^{* * *}$ \\
\hline
\end{tabular}

Notes: the value in the table is the value of the test statistic. ${ }^{* * *}$ indicates significance at the $1 \%$ level, and lhealth, lpm25 and lpwater are the logarithmic form of health, pm25 and pwater. No trend means not including a time trend in the unit root test model, trend means including a time trend in the unit root test model.

Table 3. The results of two-variable Granger causality test (1998-2017).

\begin{tabular}{|c|c|c|c|c|c|c|}
\hline \multirow[t]{2}{*}{ Variables } & \multicolumn{2}{|c|}{ Regulation $\rightarrow$ Lhealth $^{\text {a }}$} & \multicolumn{2}{|c|}{ Regulation $\rightarrow$ Env $^{b}$} & \multicolumn{2}{|c|}{ Env $\rightarrow$ Lhealth $^{c}$} \\
\hline & $\bar{Z}$ & $\widetilde{Z}$ & $\bar{Z}$ & $\widetilde{Z}$ & $\bar{Z}$ & $\widetilde{Z}$ \\
\hline env $=\operatorname{lpm} 25$ & & & & & $3.845^{* * *}$ & $2.576^{* * *}$ \\
\hline$p$-values & & & & & 0.000 & 0.010 \\
\hline regulation $=$ sogovcost $\mathrm{d}$ & $5.723 * * *$ & 1.082 & $6.944^{* * *}$ & 1.586 & & \\
\hline$p$-values & 0.000 & 0.279 & 0.000 & 0.113 & & \\
\hline regulation $=$ sogovinc $d$ & $6.038^{* * *}$ & 1.212 & $7.324 * * *$ & $1.743 *$ & & \\
\hline$p$-values & 0.000 & 0.226 & 0.000 & 0.081 & & \\
\hline regulation $=$ pollgovcost $d$ & $3.766^{* * *}$ & 1.950 * & $1.953 *$ & -0.472 & & \\
\hline$p$-values & 0.000 & 0.051 & 0.051 & 0.636 & & \\
\hline regulation $=$ pollgovinc $\mathrm{d}$ & $3.997 * * *$ & $2.113^{* *}$ & $1.868 *$ & -0.507 & & \\
\hline$p$-values & 0.000 & 0.035 & 0.062 & 0.612 & & \\
\hline env $=$ lpwater & & & & & $5.972 * * *$ & 1.185 \\
\hline$p$-values & & & & & 0.000 & 0.236 \\
\hline regulation $=$ watergovcost $\mathrm{e}$ & 1.324 & -0.732 & $61.544^{* * *}$ & $24.103^{* * *}$ & & \\
\hline$p$-values & 0.185 & 0.464 & 0.000 & 0.000 & & \\
\hline regulation $=$ watergovinc $\mathrm{e}^{\mathrm{e}}$ & 1.289 & -0.746 & $58.910^{* * *}$ & $23.016^{* * *}$ & & \\
\hline$p$-values & 0.197 & 0.455 & 0.000 & 0.000 & & \\
\hline regulation $=$ pollgovcost $\mathrm{e}$ & $3.766^{* * *}$ & 1.950 * & $35.268^{* * *}$ & $13.267^{* * *}$ & & \\
\hline$p$-values & 0.000 & 0.051 & 0.000 & 0.000 & & \\
\hline regulation $=$ pollgovinc $\mathrm{e}$ & $3.997 * * *$ & $2.113^{* *}$ & $34.799 * * *$ & $13.073^{* * *}$ & & \\
\hline$p$-values & 0.000 & 0.035 & 0.000 & 0.000 & & \\
\hline
\end{tabular}

Notes: a - The Granger causal effect of environmental regulations on public health costs. ${ }^{\mathrm{b}}$ - The Granger causal effect of environmental regulations on environmental pollution. c-The Granger causal effect of environmental pollution on public health costs. ${ }^{\mathrm{d}}$-When environmental pollution is measured by $\mathrm{PM}_{2.5}$, the environmental regulations are measured by the proportion of waste gas and industrial pollution control costs in industrial enterprises' main business costs and main business income, respectively. ${ }^{\mathrm{e}}$-When environmental pollution is measured by per capita wastewater discharge, the environmental regulation is measured by the proportion of wastewater and industrial pollution control costs in industrial enterprises' main business costs and main business income, respectively. ***,** and ${ }^{*}$ denote significance at the $1 \%, 5 \%$ and $10 \%$ levels, respectively, and lhealth, lpm25 and lpwater are the logarithmic form of health, pm 25 and pwater. To avoid the arbitrary, all the lag order of the Granger test in this study was chosen by the bayesian information criterion (BIC) criterion. 
Furthermore, this study examined the Granger causal effect of environmental regulations on public health costs with fixed environmental pollution, and the Granger causal effect of environmental pollution on public health costs with fixed environmental regulations. The results in Table 4 are based on Equation (12). It should be noted that the general method of examining the panel Granger causality test in a three-variable case did not appear in Dumitrescu and Hurlin [42]. Therefore, this study converts the three-variable panel Granger causality test into a two-variable panel Granger causality test based on the Frisch-Waugh theorem. Specifically, this study used the residuals from regressing public health costs and regressing environmental regulations on environmental pollution to test whether there is a Granger causal effect of environmental regulations on public health costs after controlling for environmental pollution. With the same method, whether environmental pollution has a Granger causal effect on public health costs after controlling for environmental regulations can be tested. The results in Table 4 indicate that after controlling for environmental pollution, environmental regulations measured by waste gas treatment have a moderate causal effect on public health costs (the corresponding $p$ value of the $\bar{Z}$ statistic is small), while after controlling for environmental regulations, there is a significant causal effect of environmental pollution on public health costs. It is noted that after controlling for wastewater discharge, environmental regulations measured by wastewater treatment can still explain public health costs, which means such environmental regulations can affect public health costs through other channels.

Table 4. The results of three-variable Granger causality test (1998-2017).

\begin{tabular}{ccccc}
\hline Variables & Regulation $\rightarrow$ Lhealth|Pollution & \multicolumn{2}{c}{ Pollution $\rightarrow$ Lhealth|Regulation } \\
\hline env $=$ lpm25 & $\bar{Z}$ & $\widetilde{Z}$ & $\bar{Z}$ & $\widetilde{Z}$ \\
\hline$p$-values & & & & \\
regulation $=$ sogovcost & 1.275 & 0.565 & $3.269^{* * *}$ & 1.600 \\
regulation = sogovinc & 0.202 & 0.572 & 0.001 & 0.110 \\
$p$-values & 1.328 & 0.607 & $3.222^{* * *}$ & 1.567 \\
regulation $=$ pollgovcost & 0.184 & 0.544 & 0.001 & 0.117 \\
$p$-values & $2.659^{* * *}$ & $1.648^{*}$ & $2.439^{* *}$ & 1.016 \\
regulation $=$ pollgovinc & 0.008 & 0.099 & 0.015 & 0.310 \\
$p$-values & $2.523^{* *}$ & 1.541 & $2.504^{* *}$ & 1.062 \\
env $=$ lpwater & 0.012 & 0.123 & 0.012 & 0.288 \\
\hline regulation $=$ watergovcost & $2.558^{* *}$ & & & -0.216 \\
$p$-values & 0.010 & 1.569 & $2.575^{* * *}$ & 0.829 \\
regulation $=$ watergovinc & $2.520^{* *}$ & 0.117 & 0.010 & -0.232 \\
$p$-values & 0.012 & 1.539 & $2.536^{* *}$ & 0.817 \\
regulation $=$ pollgovcost & $1.796^{*}$ & 0.124 & 0.011 & -0.253 \\
$p$-values & 0.073 & 0.206 & $2.485^{* *}$ & 0.800 \\
regulation $=$ pollgovinc & $1.983^{* *}$ & 0.331 & 0.013 & -0.159 \\
$p$-values & 0.047 & 1.119 & $2.714^{* * *}$ & 0.874 \\
\hline
\end{tabular}

Notes: ***,** and * denote significance at the $1 \%, 5 \%$ and $10 \%$ levels, respectively, and lhealth, lpm 25 and lpwater are the logarithmic form of health, pm25 and pwater. To avoid the arbitrary, all the lag order of the Granger test in this study was chosen by the BIC criterion.

\subsection{Results of Mediation Effect Model}

The limitation of the Granger causality test is that it can only describe the dynamic correlation among economic variables [44]. Therefore, this study used the mediation effect model to reveal the mechanism "environmental regulations $\rightarrow$ environmental quality $\rightarrow$ health level", i.e., determine whether environmental regulations improve public health by reducing pollutant emissions. Table 5 shows the results of this model corresponding to Equation (4)—environmental regulations (i.e., waste gas treatment, wastewater treatment, and total pollution control) have a significant negative impact on public health costs, which means environmental regulations can improve public health or produce 
health co-benefits (the estimated parameter is negative and significant, which means environmental regulations can decrease public health costs). This result is consistent with the results of the Granger causality test. Our findings are consistent with those of Diaz-Mendez, et al. [45], Do, et al. [9], Jones [8] and Tanaka [24]. Furthermore, the results in Columns (7) and (8) show that the health co-benefits produced by environmental regulations measured by wastewater treatment are more significant than when measured by waste gas treatment. The estimated coefficient of environmental regulations measured by waste gas treatment is still negative but not significant. At the same time, the estimated coefficients in Columns (8) and (9) show that, after controlling for environmental regulations measured by wastewater treatment, the absolute value of the estimated coefficients $(-2.575$ and -3.278 , respectively) of environmental regulations decreases compared with those in Columns (6) and (7) (-2.613 and -3.314 , respectively). This indicates that some of the health co-benefits are absorbed by environmental regulations measured by waste gas treatment.

Table 5. Impacts of regulation on health expenditure (1998-2017).

\begin{tabular}{|c|c|c|c|c|c|c|c|c|}
\hline Variables & Lhealth & Lhealth & Lhealth & Lhealth & Lhealth & Lhealth & Lhealth & Lhealth \\
\hline & (1) & (2) & (3) & (4) & (5) & (6) & (7) & (8) \\
\hline sogovcost & $\begin{array}{c}-0.821 \text { ** } \\
(0.317)\end{array}$ & & & & & & $\begin{array}{l}-0.128 \\
(0.185)\end{array}$ & \\
\hline sogovinc & & $\begin{array}{c}-0.940 * * \\
(0.399)\end{array}$ & & & & & & $\begin{array}{l}-0.127 \\
(0.227)\end{array}$ \\
\hline pollgovcost & & & $\begin{array}{c}-1.201 * * * \\
(0.180)\end{array}$ & & & & & \\
\hline pollgovinc & & & & $-1.493^{* * *}$ & & & & \\
\hline & & & & $(0.247)$ & & & & \\
\hline watergovcost & & & & & $\begin{array}{c}-2.613^{* * *} \\
(0.550)\end{array}$ & & $\begin{array}{c}-2.575^{* * *} \\
(0.525)\end{array}$ & \\
\hline watergovinc & & & & & & $\begin{array}{c}-3.314^{* * *} \\
(0.784)\end{array}$ & & $\begin{array}{c}-3.278^{* * * *} \\
(0.756)\end{array}$ \\
\hline Constant & $\begin{array}{l}6.284^{* * *} \\
(0.0355)\end{array}$ & $\begin{array}{l}6.277^{* * *} \\
(0.0360)\end{array}$ & $\begin{array}{l}6.462 * * * \\
(0.0405)\end{array}$ & $\begin{array}{l}6.461^{* * *} \\
(0.0446)\end{array}$ & $\begin{array}{l}6.389 * * * \\
(0.0415)\end{array}$ & $\begin{array}{l}6.392 * * * \\
(0.0473)\end{array}$ & $\begin{array}{l}6.401^{* * *} \\
(0.0502)\end{array}$ & $\begin{array}{l}6.401^{* * *} \\
(0.0557)\end{array}$ \\
\hline FE & YES & YES & YES & YES & YES & YES & YES & YES \\
\hline $\mathrm{N}$ & 600 & 600 & 600 & 600 & 600 & 600 & 600 & 600 \\
\hline $\mathrm{F}$ & 6.716 & 5.549 & 44.41 & 36.42 & 22.56 & 17.86 & 12.47 & 9.800 \\
\hline $\mathrm{R}^{2}$ & 0.0299 & 0.0254 & 0.213 & 0.207 & 0.275 & 0.276 & 0.276 & 0.277 \\
\hline Adjusted- $\mathrm{R}^{2}$ & 0.0283 & 0.0238 & 0.212 & 0.205 & 0.274 & 0.275 & 0.273 & 0.274 \\
\hline
\end{tabular}

Notes: Roust standard errors clustered at the province level are reported in parentheses, and lhealth is the logarithmic form of health. ${ }^{* * *}$ and ${ }^{* *}$ denote significance at the $1 \%$ and $5 \%$ levels, respectively. FE is the fixed effect, $\mathrm{N}$ is the sample size, $\mathrm{F}$ is the F-test value, $\mathrm{R}^{2}$ is the goodness of fit and Adjusted- $\mathrm{R}^{2}$ is the adjusted goodness of fit.

Table 6 shows the results of the mediation effect models corresponding to Equation (5)—the impact of environmental regulations on environmental pollution, with Columns (1)-(4) presenting the impact of environmental regulations on $\mathrm{PM}_{2.5}$ and Columns (5)-(8) on wastewater discharge. From Table 6, environmental regulations (i.e., waste gas treatment and total pollution control) can significantly improve the atmospheric environment (the estimated parameter is negative and significant). Environmental regulations (i.e., wastewater treatment and total pollution control) have also significantly improved the water environment (the estimated parameter is negative and significant). As is known, pollutants are mainly emitted by enterprises, and the negative and significant parameter indicates that these enterprises carried out the emission reduction work when facing environmental regulations. Our findings are similar to those of Auffhammer, et al. [16], Greenstone and Hanna [17], Li, et al. [10], and Yao, et al. [18]. 
Table 6. Impacts of regulation on pollutants (1998-2017).

\begin{tabular}{|c|c|c|c|c|c|c|c|c|}
\hline Variables & Lpm25 & Lpm25 & Lpm25 & Lpm25 & Lpwater & Lpwater & Lpwater & Lpwater \\
\hline & (1) & (2) & (3) & (4) & (5) & (6) & (7) & (8) \\
\hline sogovcost & $\begin{array}{c}-0.420 * * * \\
(0.128)\end{array}$ & & & & & & & \\
\hline sogovinc & & $\begin{array}{c}-0.481^{* * *} \\
(0.156)\end{array}$ & & & & & & \\
\hline pollgovcost & & & $\begin{array}{c}-0.544^{* * *} \\
(0.0979)\end{array}$ & & & & $\begin{array}{c}-0.871^{* * *} \\
(0.181)\end{array}$ & \\
\hline pollgovinc & & & & $\begin{array}{c}-0.669 * * * \\
(0.131)\end{array}$ & & & & $\begin{array}{c}-1.119 * * * \\
(0.223)\end{array}$ \\
\hline watergovcost & & & & & $\begin{array}{c}-1.514^{* * *} \\
(0.504)\end{array}$ & & & \\
\hline watergovinc & & & & & & $\begin{array}{c}-2.002 * * * \\
(0.646)\end{array}$ & & \\
\hline Constant & $\begin{array}{l}3.370 * * * \\
(0.0143)\end{array}$ & $\begin{array}{l}3.366^{* * *} \\
(0.0141)\end{array}$ & $\begin{array}{l}3.445^{* * *} \\
(0.0220)\end{array}$ & $\begin{array}{l}3.444^{* * *} \\
(0.0237)\end{array}$ & $\begin{array}{l}3.746^{* * *} \\
(0.0381)\end{array}$ & $\begin{array}{l}3.752 * * * \\
(0.0390)\end{array}$ & $\begin{array}{l}3.827^{* * *} \\
(0.0406)\end{array}$ & $\begin{array}{l}3.833^{* * *} \\
(0.0402)\end{array}$ \\
\hline $\mathrm{FE}$ & YES & YES & YES & YES & YES & YES & YES & YES \\
\hline $\mathrm{N}$ & 600 & 600 & 600 & 600 & 600 & 600 & 600 & 600 \\
\hline $\mathrm{F}$ & 10.82 & 9.491 & 30.89 & 25.89 & 9.005 & 9.620 & 23.21 & 25.17 \\
\hline $\mathrm{R}^{2}$ & 0.0230 & 0.0195 & 0.128 & 0.122 & 0.0404 & 0.0442 & 0.0491 & 0.0509 \\
\hline Adjusted- $\mathrm{R}^{2}$ & 0.0214 & 0.0178 & 0.127 & 0.121 & 0.0388 & 0.0426 & 0.0475 & 0.0493 \\
\hline
\end{tabular}

Notes: Roust standard errors clustered at the province level are reported in parentheses, and lpm25 and lpwater are the logarithmic form of pm 25 and pwater. ${ }^{* * * *}$ denote significance at the $1 \%$ levels. FE is the fixed effect, $\mathrm{N}$ is the sample size, $\mathrm{F}$ is the F-test value, $\mathrm{R}^{2}$ is the goodness of fit and Adjusted- $\mathrm{R}^{2}$ is the adjusted goodness of fit.

Table 7 shows the results of the mediation effect model corresponding to Equation (6), which reveals whether environmental regulations reduce public health costs by improving environmental quality. The results in Columns (1) and (2) show that $\mathrm{PM}_{2.5}$ can significantly increase public health costs (the estimated parameter is positive and significant). Environmental regulations measured by waste gas treatment become nonsignificant (the corresponding estimated parameter is negative and nonsignificant) after controlling for $\mathrm{PM}_{2.5}$ emissions and the absolute values of the coefficients $(-0.337$ and -0.385 , respectively) are smaller than those in Columns (2) and (3) in the Table 5 ( -0.821 and -0.940 , respectively). The parameter of lpm25 is significant, while that of sogovcost (or sogovinc) is nonsignificant, which is consistent with the definition of a full mediation effect in Section 3.1. In other words, environmental regulations measured by waste gas treatment reduce public health costs only through improvement in air quality, thus producing health co-benefits. The results in Columns (3) and (4) show that wastewater could significantly increase public health costs (the corresponding estimated parameter is negative and significant). After controlling for wastewater discharge, environmental regulations measured by wastewater treatment are still significant. However, the absolute values of the estimated coefficients ( -2.436 and -3.086 , respectively) are smaller than those of the corresponding coefficients ( -2.613 and -3.314 , respectively) in Columns (6) and (7) in Table 5 , and both the parameters of lpwater and watergovcost (or watergovinc) are significant, which is in line with the definition of a partial mediation effect in Section 3.1. In other words, environmental regulations measured by wastewater treatment can not only reduce social health costs by improving the water environment, thus creating health co-benefits, but also through other channels. 
Table 7. Impacts of regulation on health expenditure by fixing pollutants (1998-2017).

\begin{tabular}{|c|c|c|c|c|c|c|c|c|}
\hline Variables & Lhealth & Lhealth & Lhealth & Lhealth & Lhealth & Lhealth & Lhealth & Lhealth \\
\hline & (1) & (2) & (3) & (4) & (5) & (6) & (7) & (8) \\
\hline lpm25 & $\begin{array}{l}1.153^{* * *} \\
(0.0733)\end{array}$ & $\begin{array}{l}1.156^{* * *} \\
(0.0735)\end{array}$ & & & $\begin{array}{c}0.945^{* * *} \\
(0.0737)\end{array}$ & $\begin{array}{c}0.946^{* * *} \\
(0.0760)\end{array}$ & $\begin{array}{c}0.994^{* * *} \\
(0.0711)\end{array}$ & $\begin{array}{l}1.000^{* * *} \\
(0.0705)\end{array}$ \\
\hline lpwater & & & $\begin{array}{l}0.117^{* * *} \\
(0.0271)\end{array}$ & $\begin{array}{l}0.114^{* * *} \\
(0.0267)\end{array}$ & $\begin{array}{c}0.0727^{* * *} \\
(0.0193)\end{array}$ & $\begin{array}{c}0.0704^{* * *} \\
(0.0192)\end{array}$ & $\begin{array}{c}0.0741^{* * *} \\
(0.0219)\end{array}$ & $\begin{array}{c}0.0736^{* * *} \\
(0.0217)\end{array}$ \\
\hline sogovcost & $\begin{array}{c}-0.337 \\
(0.239)\end{array}$ & & & & $\begin{array}{l}0.0193 \\
(0.183)\end{array}$ & & & \\
\hline sogovinc & & $\begin{array}{l}-0.385 \\
(0.304)\end{array}$ & & & & $\begin{array}{l}0.0385 \\
(0.228)\end{array}$ & & \\
\hline watergovcost & & & $\begin{array}{c}-2.436^{* * *} \\
(0.519)\end{array}$ & & $\begin{array}{c}-1.458^{* * *} \\
(0.261)\end{array}$ & & & \\
\hline watergovinc & & & & $\begin{array}{c}-3.086^{* * *} \\
(0.745)\end{array}$ & & $\begin{array}{c}-1.869 * * * \\
(0.385)\end{array}$ & & \\
\hline pollgovcost & & & & & & & $\begin{array}{c}-0.596^{* * *} \\
(0.114)\end{array}$ & \\
\hline pollgovinc & & & & & & & & $\begin{array}{c}-0.741^{* * *} \\
(0.153)\end{array}$ \\
\hline Constant & $\begin{array}{c}2.397 * * * \\
(0.242)\end{array}$ & $\begin{array}{c}2.384 * * * \\
(0.242)\end{array}$ & $\begin{array}{l}5.951 * * * \\
(0.0996)\end{array}$ & $\begin{array}{c}5.965^{* * *} \\
(0.103)\end{array}$ & $\begin{array}{c}2.897^{* * *} \\
(0.249)\end{array}$ & $\begin{array}{c}2.902 * * * \\
(0.263)\end{array}$ & $\begin{array}{c}2.753^{* * *} \\
(0.239)\end{array}$ & $\begin{array}{c}2.736^{* * *} \\
(0.238)\end{array}$ \\
\hline FE & YES & YES & YES & YES & YES & YES & YES & YES \\
\hline $\mathrm{N}$ & 600 & 600 & 600 & 600 & 600 & 600 & 600 & 600 \\
\hline $\mathrm{F}$ & 123.8 & 124.1 & 123.8 & 16.02 & 107.5 & 110.8 & 115.1 & 113.5 \\
\hline $\mathrm{R}^{2}$ & 0.472 & 0.472 & 0.472 & 0.305 & 0.560 & 0.561 & 0.533 & 0.532 \\
\hline Adjusted-R ${ }^{2}$ & 0.471 & 0.470 & 0.471 & 0.302 & 0.557 & 0.558 & 0.531 & 0.530 \\
\hline
\end{tabular}

Notes: Roust standard errors clustered at the province level are reported in parentheses, ${ }^{* * *}$ denote significance at the $1 \%$ levels, and lhealth, lpm 25 and lpwater are the logarithmic form of health, pm 25 and pwater. FE is the fixed effect, $\mathrm{N}$ is the sample size, $\mathrm{F}$ is the F-test value, $\mathrm{R}^{2}$ is the goodness of fit and adjusted- $\mathrm{R}^{2}$ is the adjusted goodness of fit.

After considering two pollutants and two environmental regulations together, Columns (5) and (6) in Table 7 suggest that the partial mediation effect still exists in environmental regulations measured by wastewater treatment; however, the effect of environmental regulations measured by waste gas treatment becomes positive without becoming significant. One possible reason is the multicollinearity among environmental regulations measured by waste gas treatment and wastewater treatment, which leads to the effect of waste gas treatment being absorbed by that of wastewater treatment. Columns (7) and (8) further test the effect of environmental regulations measured by total pollution control on $\mathrm{PM}_{2.5}$ and wastewater. The results show that there is a partial mediation effect, i.e., total pollution control could reduce public health costs by improving the atmospheric environment and water environment, and at the same time, also generate health co-benefits through other channels.

\section{Discussion}

According to Tables 4 and 7, environmental regulations can reduce public health costs through their effect on $\mathrm{PM}_{2.5}$ and wastewater, because environmental regulations can influence pollutants [10,16-18] and pollutants can influence public health $[1,11,12,14]$. That is, our findings are easy to understand and we can regard environmental quality as a "bridge" to link environmental regulations with public health. This study can provide valuable policy insights, particularly for improving public health by taking on environmental regulation policies to reduce pollutants. Additionally, from Table 7 , it is worth noting that the coefficient of $\mathrm{PM}_{2.5}$ in Columns (1) and (2) is approximately 10 times larger than the coefficient of wastewater in Columns (3) and (4), which indicates that air pollution has a greater impact on health. The conclusions from Columns (5) to (8) are similar. The findings indicate that environmental regulation policies should pay more attention to the treatment of waste gas, which reveals to some extent why China attaches great importance to the atmospheric environment and has successively promulgated many rules and regulations for atmospheric environmental governance. This study quantitatively 
evaluates the three-dimensional relationship between "environmental regulations, environmental quality, and public health", taking the environmental quality as a "bridge". It is different from previous studies, such as those by Auffhammer, et al. [16] and Li, et al. [10], which quantitatively evaluated the effects of environmental regulations on pollutants with a separated model, as well as those by Beatty and Shimshack [11], Arceo, et al. [1], and Kim, et al. [13], which quantitatively evaluated the effects of environmental pollution on health, also with a separated model. In other words, the main features in the existing literature only studied two variables comprehensively. Almost no study has constructed a rigorous econometric model to quantitatively evaluate the causal relationship between environmental regulations, environmental quality, and public health. However, this study uses a mediation effect model different from the previous studies to test the mechanism "environmental regulations $\rightarrow$ environmental quality $\rightarrow$ health level" more rigorously. By using this new model, this study finds that environmental regulations can create health co-benefits through improvements in environmental quality.

However, it has some limitations that need to be addressed in the future. First, this study needs to be improved on by using the microdata. To do this, gathering microscopic individual data of health and using the program evaluation methods are appropriate ways to proceed. Second, this study only explains that environmental regulations measured by wastewater treatment can reduce public health costs through other channels-it does not discuss what these "other channels" are. Future research can collect more detailed data and use more solid economic knowledge to interpret these "other channels".

\section{Conclusions and Policy Applications}

Using the panel data of 30 Chinese provinces from 1998 to 2017, this study adopts the panel Granger causality model and a mediation effect model to test the mechanism "environmental regulations $\rightarrow$ environmental pollution $\rightarrow$ health costs". The results are as follows. First, environmental regulations have a Granger causal effect on health costs and environmental pollution. Second, environmental regulations measured by waste gas treatment reduce social health costs by improving the quality of the atmospheric environment, thus producing health co-benefits. Environmental regulations measured by wastewater treatment can not only reduce public health costs by improving the water environment but also through other channels. Total pollution control can reduce public health costs by improving the atmospheric environment and water environment. At the same time, it can also generate health co-benefits through other channels. In addition, the study also shows that air pollution has a greater impact on health than wastewater, and environmental regulation policies should pay more attention to the treatment of waste gas. All in all, environmental regulations can not only reduce pollutant emissions but also produce health co-benefits through said reduction. These findings provide important empirical evidence for developing countries to manage their environmental quality and, thus, enhance their social welfare.

Based on the above findings, the policy applications are as follows. Firstly, the government should continue to implement air pollution control policies, especially $\mathrm{PM}_{2.5}$ control policies, which can greatly reduce the negative externalities caused by air pollution. It should also be noted that $\mathrm{PM}_{2.5}$ emissions are largely diffused or transferred to adjacent areas through atmospheric circulation, atmospheric chemistry, and so on; hence, controlling $\mathrm{PM}_{2.5}$ requires a synergistic mechanism among regions. Secondly, the government should improve the water environment and enforce water pollution control. The results of this study show that wastewater treatment can produce health co-benefits by improving the water environment as well as through other channels, indicating that water pollution control can create additional benefits. Lastly, the findings of this study are based on a developing country; therefore, calling for and promoting developing countries to reduce environmental pollution together can undoubtedly inhibit or reduce the risks for society and enhance social welfare.

Author Contributions: P.J. conceived the idea and developed the model, K.L. collected the data and finished the programing, L.T. analyzed the results and wrote the paper. All authors have read and agreed to the published version of the manuscript. 
Funding: This research was funded by National Natural Science Foundation of China (No. 71804044), the Social Science Foundation of Hunan Province (No. 16YBA284), the National Natural Science Foundation of Hunan Province (No. 2018JJ3353), and Beijing Finance Project (No. PXM2019-178216-000004-00341472-FCG-Innovative project-Preresearch).

Acknowledgments: We are grateful for valuable feedback to earlier versions of this paper from three anonymous reviewers.

Conflicts of Interest: The authors declare no conflict of interest.

\section{References}

1. Arceo, E.; Hanna, R.; Oliva, P. Does the Effect of Pollution on Infant Mortality Differ Between Developing and Developed Countries? Evidence from Mexico City. Econ. J. 2016, 126, 257-280. [CrossRef]

2. Yang, J.; Zhang, B. Air pollution and healthcare expenditure: Implication for the benefit of air pollution control in China. Environ. Int. 2018, 120, 443-455. [CrossRef] [PubMed]

3. Chen, Y.; Ebenstein, A.; Greenstone, M.; Li, H. Evidence on the impact of sustained exposure to air pollution on life expectancy from China's Huai River policy. Proc. Natl. Acad. Sci. USA 2013, 110, 12936-12941. [CrossRef] [PubMed]

4. Brauer, M.; Freedman, G.; Frostad, J.; van Donkelaar, A.; Martin, R.V.; Dentener, F.; van Dingenen, R.; Estep, K.; Amini, H.; Apte, J.S.; et al. Ambient Air Pollution Exposure Estimation for the Global Burden of Disease 2013. Environ. Sci. Technol. 2016, 50, 79-88. [CrossRef] [PubMed]

5. Ostro, B.; Spadaro, J.V.; Gumy, S.; Mudu, P.; Awe, Y.; Forastiere, F.; Peters, A. Assessing the recent estimates of the global burden of disease for ambient air pollution: Methodological changes and implications for lowand middle-income countries. Environ. Res. 2018, 166, 713-725. [CrossRef]

6. Cohen, A.J.; Brauer, M.; Burnett, R.; Anderson, H.R.; Frostad, J.; Estep, K.; Balakrishnan, K.; Brunekreef, B.; Dandona, L.; Dandona, R.; et al. Estimates and 25-year trends of the global burden of disease attributable to ambient air pollution: An analysis of data from the Global Burden of Diseases Study 2015. Lancet 2017, 389, 1907-1918. [CrossRef]

7. Li, J.; Liu, H.; Lv, Z.; Zhao, R.; Deng, F.; Wang, C.; Qin, A.; Yang, X. Estimation of PM2.5 mortality burden in China with new exposure estimation and local concentration-response function. Environ. Pollut. 2018, 243, 1710-1718. [CrossRef]

8. Jones, B.A. Spillover health effects of energy efficiency investments: Quasi-experimental evidence from the Los Angeles LED streetlight program. J. Environ. Econ. Manag. 2018, 88, 283-299. [CrossRef]

9. Do, Q.-T.; Joshi, S.; Stolper, S. Can environmental policy reduce infant mortality? Evidence from the Ganga Pollution Cases. J. Dev. Econ. 2018, 133, 306-325. [CrossRef]

10. Li, X.; Qiao, Y.; Zhu, J.; Shi, L.; Wang, Y. The “APEC blue" endeavor: Causal effects of air pollution regulation on air quality in China. J. Clean. Prod. 2017, 168, 1381-1388. [CrossRef]

11. Beatty, T.K.M.; Shimshack, J.P. Air pollution and children's respiratory health: A cohort analysis. J. Environ. Econ. Manag. 2014, 67, 39-57. [CrossRef]

12. Chen, K.; Wolf, K.; Breitner, S.; Gasparrini, A.; Stafoggia, M.; Samoli, E.; Andersen, Z.J.; Bero-Bedada, G.; Bellander, T.; Hennig, F.; et al. Two-way effect modifications of air pollution and air temperature on total natural and cardiovascular mortality in eight European urban areas. Environ. Int. 2018, 116, 186-196. [CrossRef] [PubMed]

13. Kim, H.; Kim, H.; Lee, J.T. Spatial variation in lag structure in the short-term effects of air pollution on mortality in seven major South Korean cities, 2006-2013. Environ. Int. 2019, 125, 595-605. [CrossRef] [PubMed]

14. Ebenstein, A.; Fan, M.; Greenstone, M.; He, G.; Zhou, M. New evidence on the impact of sustained exposure to air pollution on life expectancy from China's Huai River Policy. Proc. Natl. Acad. Sci. USA 2017, 114, 10384-10389. [CrossRef]

15. Ebenstein, A.; Fan, M.; Greenstone, M.; He, G.; Yin, P.; Zhou, M. Growth, Pollution, and Life Expectancy: China from 1991-2012. Am. Econ. Rev. Pap. Proc. 2015, 105, 226-231. [CrossRef]

16. Auffhammer, M.; Bento, A.M.; Lowe, S.E. Measuring the effects of the Clean Air Act Amendments on ambient concentrations: The critical importance of a spatially disaggregated analysis. J. Environ. Econ. Manag. 2009, 58, 15-26. [CrossRef] 
17. Greenstone, M.; Hanna, R. Environmental Regulations, Air and Water Pollution, and Infant Mortality in India. Am. Econ. Rev. 2014, 104, 3038-3072. [CrossRef]

18. Yao, L.; Wang, D.; Fu, Q.; Qiao, L.; Wang, H.; Li, L.; Sun, W.; Li, Q.; Wang, L.; Yang, X.; et al. The effects of firework regulation on air quality and public health during the Chinese Spring Festival from 2013 to 2017 in a Chinese megacity. Environ. Int. 2019, 126, 96-106. [CrossRef]

19. Wang, K.; Yin, H.; Chen, Y. The effect of environmental regulation on air quality: A study of new ambient air quality standards in China. J. Clean. Prod. 2019, 215, 268-279. [CrossRef]

20. Greenstone, M. Did the Clean Air Act cause the remarkable decline in sulfur dioxide concentrations? J. Environ. Econ. Manag. 2004, 47, 585-611. [CrossRef]

21. Wang, C.; Wu, J.; Zhang, B. Environmental regulation, emissions and productivity: Evidence from Chinese COD-emitting manufacturers. J. Environ. Econ. Manag. 2018, 92, 54-73. [CrossRef]

22. Cesur, R.; Tekin, E.; Ulker, A. Can natural gas save lives? Evidence from the deployment of a fuel delivery system in a developing country. J. Health Econ. 2018, 59, 91-108. [CrossRef] [PubMed]

23. Cesur, R.; Tekin, E.; Ulker, A. Air Pollution and Infant Mortality: Evidence from the Expansion of Natural Gas Infrastructure. Econ. J. 2017, 127, 330-362. [CrossRef]

24. Tanaka, S. Environmental regulations on air pollution in China and their impact on infant mortality. J. Health Econ. 2015, 42, 90-103. [CrossRef]

25. Baron, R.M.; Kenny, D.A. The Moderator-Mediator Variable Distinction in Social Psychological Research: Conceptual, Strategic, and Statistical Considerations. J. Personal. Soc. Psychol. 1986, 51, 1173-1182. [CrossRef]

26. Shao, S.; Zhang, K.; Dou, J. Effects of Economic Agglomeration on Energy Saving and Emission Reduction:Theory and Empirical Evidence from China. Manag. World 2019, 35, 36-60.

27. Wen, Z.; Ye, B. Analyses of Mediating Effects: The Development of Methods and Models. Adv. Psychol. Sci. 2014, 22, 731-745. [CrossRef]

28. Fritz, M.S.; Taylor, A.B.; MacKinnon, D.P. Explanation of Two Anomalous Results in Statistical Mediation Analysis. Multivar. Behav. Res. 2012, 47, 61-87. [CrossRef]

29. Yang, J.; Xu, J.; Wu, X. Income Growth, Environmental Cost and Health Problems. Econ. Res. J. 2013, 12, 17-29.

30. Levinson, A. Environmental regulations and manufacturers' location choices: Evidence from the Census of Manufactures. J. Public Econ. 1996, 62, 5-29. [CrossRef]

31. Liao, X.; Shi, X. Public appeal, environmental regulation and green investment: Evidence from China. Energy Policy 2018, 119, 554-562. [CrossRef]

32. Lanoie, P.; Patry, M.; Lajeunesse, R. Environmental regulation and productivity: Testing the porter hypothesis. J. Product. Anal. 2008, 30, 121-128. [CrossRef]

33. Shen, N.; Liao, H.; Deng, R.; Wang, Q. Different types of environmental regulations and the heterogeneous influence on the environmental total factor productivity: Empirical analysis of China's industry. J. Clean. Prod. 2019, 211, 171-184. [CrossRef]

34. Wu, G.; You, D. The influence mechanism of environmental regulation on technology innovation and green total factor productivity: Based on the moderating effect of fiscal decentralization. J. Ind. Eng. Eng. Manag. 2019, 33, 37-50.

35. Tong, J.; Liu, W.; Xue, J. Environmental Regulation, Factor Input Structure and Industrial Transformation. Econ. Res. J. 2016, 7, 43-57.

36. Song, M.; Wang, S.; Sun, J. Environmental regulations, staff quality, green technology, R\&D efficiency, and profit in manufacturing. Technol. Forecast. Soc. Chang. 2018, 133, 1-14. [CrossRef]

37. Yang, L.; Li, J. Rebound effect in China: Evidence from the power generation sector. Renew. Sustain. Energy Rev. 2017, 71, 53-62. [CrossRef]

38. Ouyang, X.; Gao, B.; Du, K.; Du, G. Industrial sectors' energy rebound effect: An empirical study of Yangtze River Delta urban agglomeration. Energy 2018, 145, 408-416. [CrossRef]

39. Harris, R.D.F.; Tzavalis, E. Inference for unit roots in dynamic panels where the time dimension is fixed. J. Econ. 1999, 91, 201-226. [CrossRef]

40. StataCorp. Stata 16 Base Reference Manual; Stata Press: College Station, TX, USA, 2019.

41. Im, K.S.; Pesaran, M.H.; Shin, Y. Testing for unit roots in heterogeneous panels. J. Econ. 2003, 115, 53-74. [CrossRef] 
42. Dumitrescu, E.-I.; Hurlin, C. Testing for Granger non-causality in heterogeneous panels. Econ. Model. 2012, 29, 1450-1460. [CrossRef]

43. Shao, S.; Li, X.; Cao, J.; Yang, L. China's Economic Policy Choices for Governing Smog Pollution Based on Spatial Spillover Effects. Econ. Res. J. 2016, 9, 73-88.

44. Chen, Q. Advanced Econometrics and Stata Applications, 2nd ed.; Higher Education Press: Beijing, China, 2014.

45. Diaz-Mendez, S.E.; Torres-Rodríguez, A.A.; Abatal, M.; Soberanis, M.A.E.; Bassam, A.; Pedraza-Basulto, G.K. Economic, environmental and health co-benefits of the use of advanced control strategies for lighting in buildings of Mexico. Energy Policy 2018, 113, 401-409. [CrossRef]

(C) 2020 by the authors. Licensee MDPI, Basel, Switzerland. This article is an open access article distributed under the terms and conditions of the Creative Commons Attribution (CC BY) license (http://creativecommons.org/licenses/by/4.0/). 